\title{
A case report of a renal liposarcoma with penile metastases
}

\author{
Benjamin Turner, Sandeep Tiwari, Malathi Gunaratne, Maruti Kumaran \\ Department of Radiology, Queen's Medical Centre, Nottingham, Nottinghamshire, United Kingdom
}

Received: April 4, 2017

DOI: $10.5430 /$ ijdi.v4n2p62
Accepted: May 24, 2017

URL: https://doi.org/10.5430/ijdi.v4n2p62

\begin{abstract}
A 73-year-old man presented to his general practitioner with a left sided abdominal mass, intermittent night sweats and left sided sciatic pain on movement. A computed tomography (CT) scan revealed a well encapsulated mass arising from the left kidney, measuring $180 \mathrm{~mm} \times 150 \mathrm{~mm}$. Following an open nephrectomy, the tumour was confirmed as being Trojani Grade II dedifferentiated liposarcoma. Repeat CTs at four months and one-year post-surgery were clear of metastases, but after 17 months the patient presented in the emergency department with severe right-sided flank pain. A CT scan showed evidence of metastatic recurrence in the lungs, sternum and right quadratus lumborum muscle. The patient was treated with palliative radiotherapy and a repeat CT taken to assess the rate of disease progression showed a new metastatic deposit within the right penile corpus cavernosum.
\end{abstract}

Key Words: Liposarcoma, Penile metastasis, Corpus cavernosum

\section{BACKGROUND}

Liposarcoma is a connective tissue malignancy arising from lipoblast cells, which has a characteristic appearance on imaging studies, particularly the Magnetic Resonance Imaging (MRI). ${ }^{[1]}$

They account for at least $20 \%$ of adult soft tissue sarcomas and occur in many tissue types, including fat, muscle, bone, retroperitoneum and viscera. They have a peak incidence between 50 and 65 years of age and can occur anywhere in the body, although they are most common in the thigh and retroperitoneum. ${ }^{[2]}$

\section{CASE REPORT}

A 73-year-old man presented to his general practitioner in May 2013 with a left sided abdominal mass, one-year history of intermittent night sweats and suffered from left sided sciatic pain on movement. The past medical history included ulcerative colitis and a myocardial infarction in 1999.

The patient was referred to urology clinic, where he was found to have large mobile renal mass lesion in the upper left abdomen. An urgent computed tomography (CT) scan of his chest, abdomen and pelvis was requested which showed a well encapsulated mass arising from the abnormally positioned left kidney (see Figures 1a \& 1b). The mass measured $180 \mathrm{~mm} \times 150 \mathrm{~mm}$ in axial diameter, extending from the inferior pole of the kidney to the level of the left sciatic notch. The mass had mixed soft tissue and fatty attenuation and a $51 \mathrm{~mm}$ simple cyst was seen within the upper pole of the left kidney. There was no evidence of metastatic disease.

Due to the fat content of the mass, it was initially thought to be an angiomyolipoma and the patient was reviewed at a urology multidisciplinary team (MDT) meeting in early June

\footnotetext{
*Correspondence: Sandeep Tiwari; Email: drsandytiwari@gmail.com; Address: Specialty Registrar in Radiology 19, Pioneer Place, Castle Hill, New South Wales, 2154, Australia.
} 
2013. The uroradiologist felt that the mass was atypical for an angiomyolipoma and that there was a possibility of it being a liposarcoma. The patient was subsequently discussed at a sarcoma MDT, where the appearance of the mass was also thought to be typical for a liposarcoma. The plan from the sarcoma MDT was to proceed with a joint urology/general surgery resection regardless of histopathological subtype.

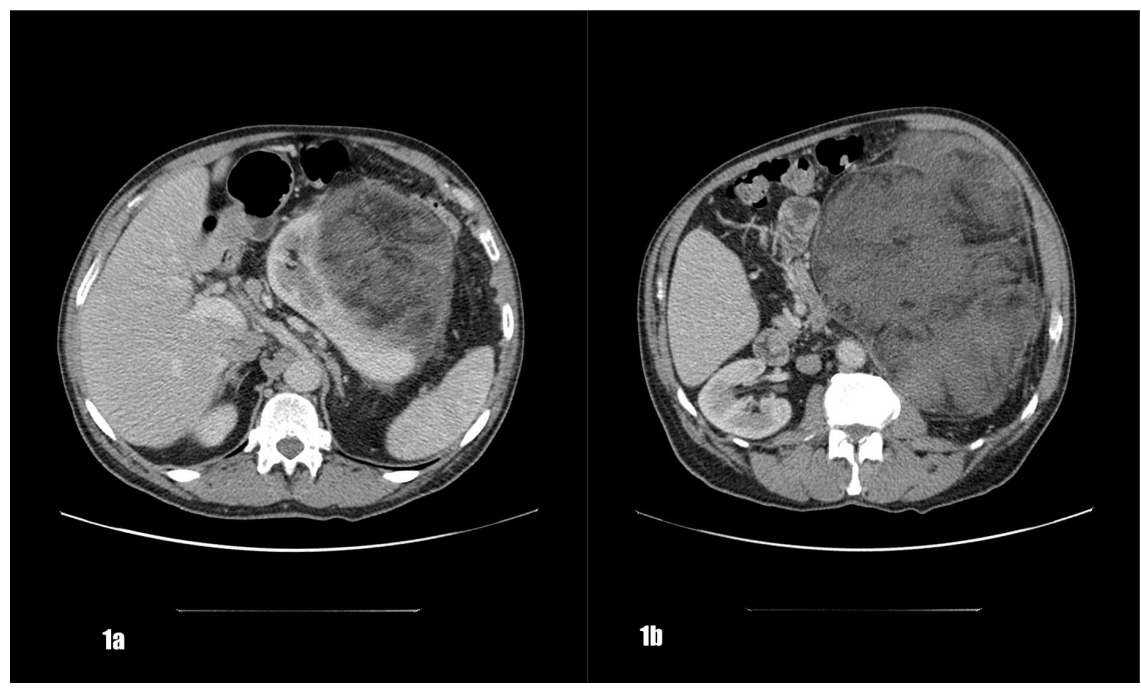

Figure 1. $2 \mathrm{~mm}$ thin slice axial MDCT showing a large mass arising from an abnormally located left kidney

A repeat CT in July to re-stage before surgery showed that the tumour had grown to $203 \mathrm{~mm} \times 166 \mathrm{~mm}$ in size. The patient underwent an open nephrectomy in July 2013 and histological analysis of the tumour showed it to be a Trojani Grade II dedifferentiated liposarcoma. There was marginal involvement but the sarcoma MDT was confident that all microscopic disease had been excised.

Repeat CTs at four months and one-year post-operation showed no evidence of local or metastatic tumour recurrence. However, in December 2014 (17 months post-operation) the patient attended the emergency department with severe right sided flank pain radiating around his right hip and across the width of his lower abdomen. CT chest, abdomen and pelvis with contrast showed evidence of metastatic tumour recurrence including an $18 \mathrm{~mm} \times 16 \mathrm{~mm}$ pulmonary nodule in the right upper lobe (see Figures $2 \mathrm{a} \& 2 \mathrm{~b}$ ), a new soft tissue mass in the region of the upper sternum measuring $35 \mathrm{~mm} \times 48 \mathrm{~mm}$ (see Figure 3) and a large soft tissue mass arising from the right quadratus lumborum muscle measuring $80 \mathrm{~mm} \times 67 \mathrm{~mm} \times 111 \mathrm{~mm}$ (see Figure 4). The quadratus lumborum mass had a very similar appearance to the initial liposarcoma.

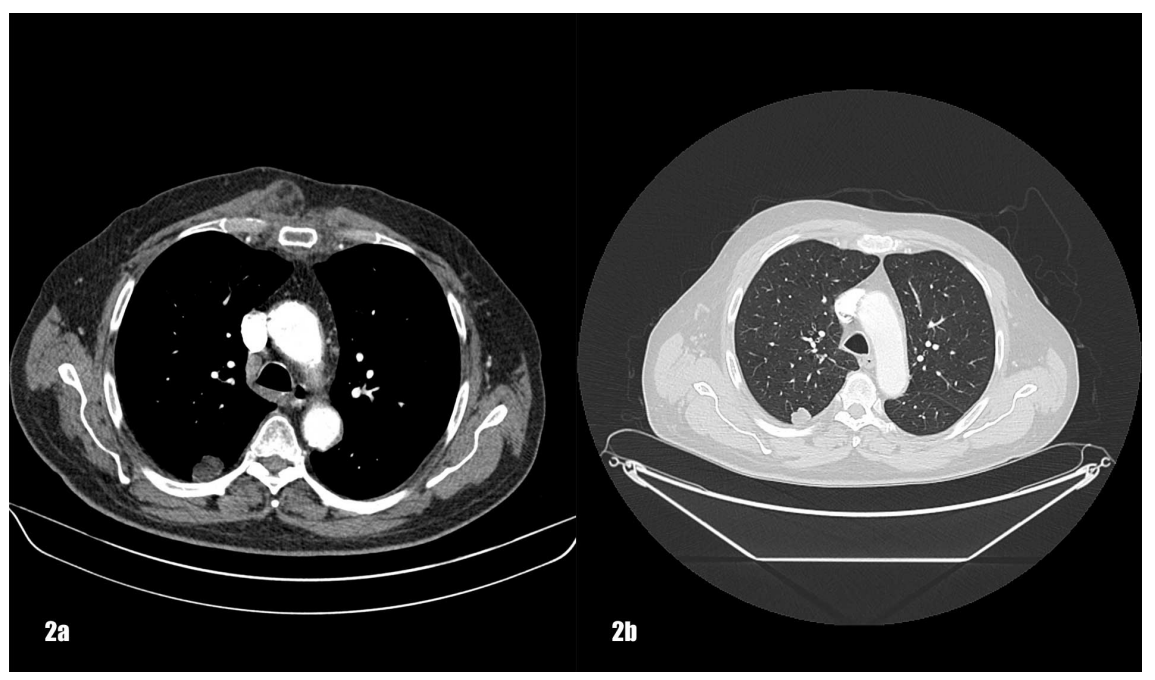

Figure 2. $2 \mathrm{~mm}$ thin slice axial MDCT showing a small right upper lobe fatty pulmonary nodule 


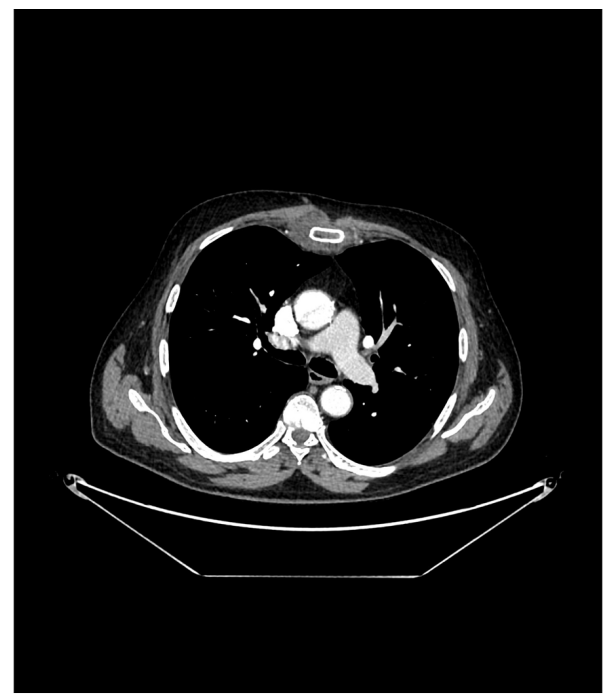

Figure 3. $2 \mathrm{~mm}$ thin slice axial MDCT showing a soft tissue mass around upper sternum

The patient was treated with palliative radiotherapy 20Gy in 5 fractions to the right flank in January 2015. In March he underwent another $\mathrm{CT}$ chest, abdomen, pelvis with contrast to assess the pace of disease progression. This showed considerable progression of the metastases with a pathological fracture of the body of the sternum (see Figures $5 a \& 5 b$ ), further predominantly fatty pulmonary nodules (see Figure 6) and an enlarged right sided retroperitoneal fat density lesion (see Figure 7). There was also an unusual metastatic deposit within the right penile corpus cavernosum (see Figures 8a \& $8 b)$.

Subsequent CTs showed progression of metastatic deposits including the penile metastasis.

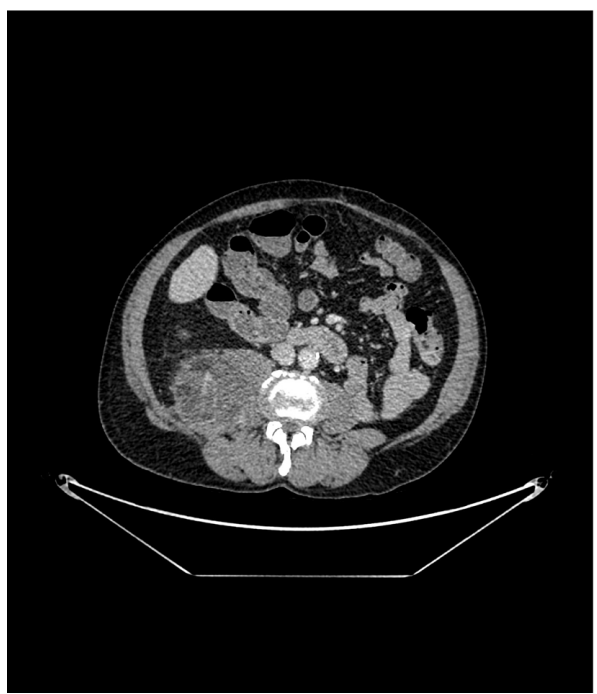

Figure 4. $2 \mathrm{~mm}$ thin slice axial MDCT showing a mass arising from right quadratus lumborum muscle

There was no documented clinical abnormality at the time of first diagnosis of the penile lesion on the CT scan. No other imaging was performed for the penile lesion. All these lesions were fat density on the CT scan and had a similar appearance to the initial left renal liposarcoma.

\section{Discussion}

Retroperitoneal/perirenal/renal liposarcoma is a rare but well recognised tumour and has been described in the literature. ${ }^{[3,4]}$

Here we reported a case of renal liposarcoma with retroperitoneal recurrence and penile metastasis. The penile lesion was not initially detected clinically and was first diagnosed on the CT scan.

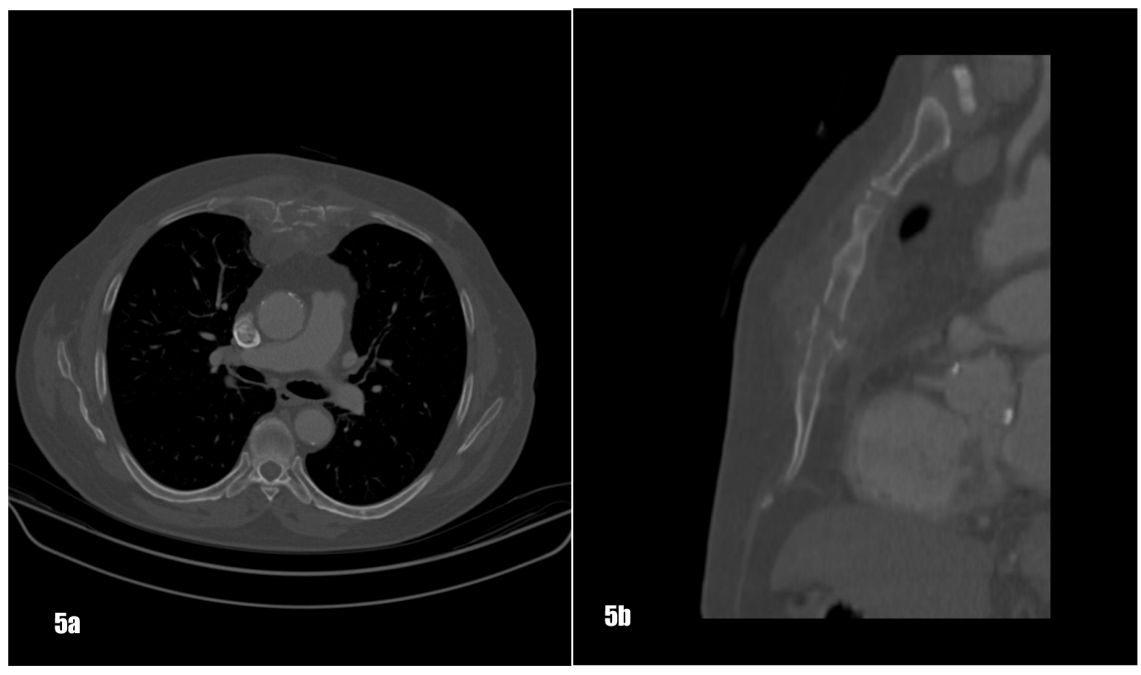

Figure 5. $2 \mathrm{~mm}$ thin slice axial and sagittal MDCT showing progression of sternal metastases with a fracture 




Figure 6. $2 \mathrm{~mm}$ thin slice axial MDCT showing further fatty pulmonary nodules

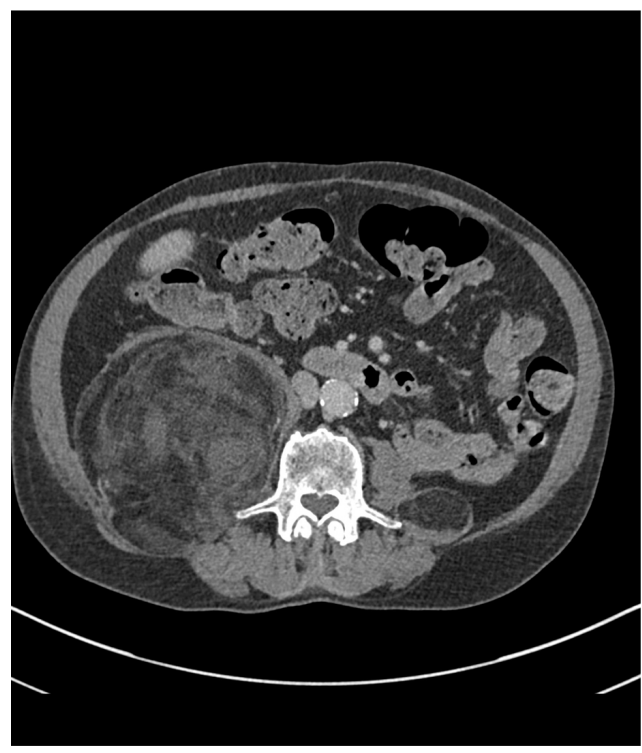

Figure 7. $2 \mathrm{~mm}$ thin slice axial MDCT showing enlarged right retroperitoneal fat density mass

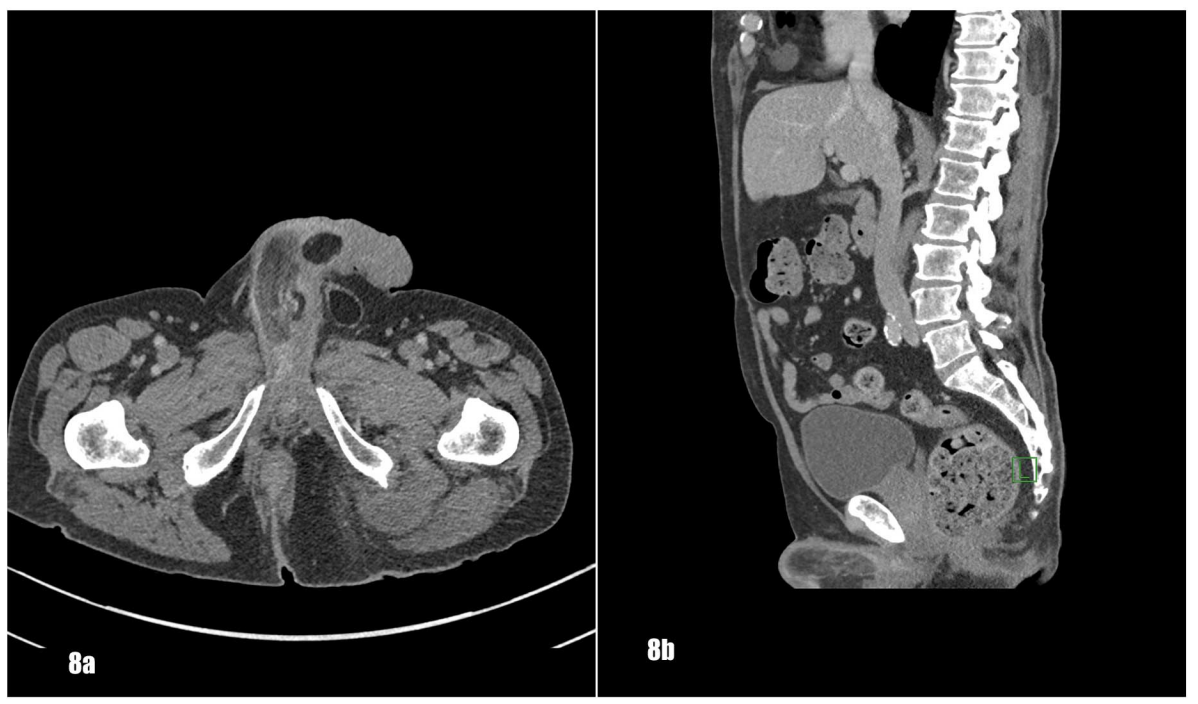

Figure 8. 8a: $2 \mathrm{~mm}$ thin slice axial MDCT showing an unusual metastatic deposit within the right penile corpus cavernosum, 8b: $2 \mathrm{~mm}$ thin slice sagittal MDCT showing an unusual metastatic deposit within the right penile corpus cavernosum

While dedifferentiated liposarcoma has a high propensity for local recurrence (40\%-80\% of patients) ${ }^{[5]}$ even after extensive surgery, metastases are rare (1\%-18\% of patients). ${ }^{[6]}$

Metastases often result in a rapidly fatal $\operatorname{course}^{[7]}$ and retroperitoneal liposarcomas are considered to be the most aggressive and poor prognosis tumours. ${ }^{[8]}$ The most common sites of metastases are lung/pleura, somatic soft tissue, lymph nodes, liver and bone. ${ }^{[6,8]}$

Penile metastases from a cancer is rare however it has been previously reported in the literature from the colorectal can-

Published by Sciedu Press cer, ${ }^{[9]}$ prostate cancer, genitourinary tract, osteosarcoma and cholangiocarcinoma. ${ }^{[10]}$

In our case there were multiple metastases including penile involvement. All these lesions were fat density on CT scan and appeared similar to the initial renal liposarcoma. Further histological confirmation was not obtained.

\section{LEARNING POINT}

Penile involvement with carcinoma by direct invasion has been reported in literature. It is unusual to have metastasis 
to penis particularly in case of liposarcoma. In our case we present unusual site of metastasis for liposarcoma. It is important to be aware that liposarcomas can metastasise to unusual locations including the corpus cavernosum and an extra attention should be paid during clinical and radiological assessment.

\section{CONFlicts OF InTEREST Disclosure}

Written informed consent was obtained from the patient for publication of this case report, including accompanying images. The authors declare that they have no conflict of interest.

\section{REFERENCES}

[1] Mankin H, et al. Liposarcoma: a soft tissue tumor with many presentations. Musculoskeletal Surgery. 2014; 98: 171-177. PMid:25047632 https://doi.org/10.1007/s12306-014-0332-1

[2] Singer S, et al. Soft Tissue Sarcoma. In: DeVita, V. et al. (eds.) DeVita, Hellman, and Rosenberg's Cancer: Principles \& Practice of Oncology. 10th ed. Philadelphia, USA: Lippincott Williams \& Wilkins; 2015. 1260 p.

[3] Liu Z, et al. A case report of huge perirenal liposarcoma associated with renal cell carcinoma and reviews of three previous cases. Int $\mathrm{L}$ Clin Exp. Med. 2014; 7(11): 4526-4529.

[4] Shastri C, et al. Renal dedifferentiated liposarcoma with intracaval tumor thrombus: A rare case. Indian J Urol. 2012 Apr-Jun; 28(2): 208-210. https://doi.org/10.4103/0970-1591.98470

[5] Keung E, et al. Predictors of outcomes in patients with primary retroperitoneal dedifferentiated liposarcoma undergoing surgery. Journal of the American College of Surgeons. 2014; 218: 206217. PMid:24315890 https ://doi.org/10.1016/j.jamcolls urg. 2013.10.009

[6] Huang HY, et al. Distant metastasis in retroperitoneal dedifferentiated liposarcoma is rare and rapidly fatal: a clinicopathological study with emphasis on the low-grade myxofibrosarcoma-like pattern as an early sign of dedifferentiation. Modern Pathology. 2005; 18: 976-984. PMid:15832195 https ://doi.org/10.1038/modpathol. 3800 381

[7] Henricks WH, et al. Dedifferentiated liposarcoma: a clinicopathological analysis of 155 cases with a proposal for an expanded definition of differentiation. American Journal of Surgical Pathology. 1997; 21: 271-81. PMid:9060596 https : //doi .org/10.1097/000004 78-199703000-00002

[8] Tirumani SH, et al. Metastasis in dedifferentiated liposarcoma: Predictors and outcome in 148 patients. European Journal of Surgical Oncology. 2015; 41: 899-904. PMid:25659772 https ://doi .org/ 10.1016/j.ejso.2015.01.012

[9] Kozan AA, et al. First case of penile metastasis following abdominoperineal resection with VRAM flap reconstruction1. J Surg Case Rep. 2016; Nov 24. https ://doi .org/10.1093/jscr/rjw 182

[10] Valeria F, et al. Relevance of computed tomography and magnetic resonance imaging for penile metastasis after prostatectomy: uncommon case report and brief review of the literature. Radiology Case Rep. 2016 Sep; 11(3): 255.259 . https://doi.org/10.1016/j.radcr.2016.04.003 